\title{
ISOLAMENTO E CARACTERIZAÇÃO DE BACTÉRIAS SOLUBILIZADORAS DE FOSFATO DA RIZOSFERA DE Eucalyptus sp. ${ }^{1}$
}

André Marcos Massenssini2 ${ }^{*}$, Marcos Rogério Tótola ${ }^{3}$, Arnaldo Chaer Borges ${ }^{3}$ e Maurício Dutra Costa ${ }^{3}$

\footnotetext{
${ }^{1}$ Recebido em 22.01.2015 aceito para publicação em 01.12.2015.

${ }^{2}$ Instituto Federal Goiano, IF Goiano, Campus Iporá, Iporá, GO - Brasil. E-mail: <ammassenssini@gmail.com>.

${ }^{3}$ Universidade Federal de Viçosa, Centro de Ciências Biológicas e da Saúde, Departamento de Microbiologia, Viçosa, MG

- Brasil.E-mail:<totolaufv@gmail.com>,<chaer@ufv.br>e <mdcosta@ufv.br>.

*Autor para correspondência.
}

\begin{abstract}
RESUMO - A inoculação de micro-organismos solubilizadores de fosfato, em conjunto ou não com fungos micorrízicos, pode ser alternativa para a redução dos custos de produção de eucalipto por meio da diminuição dos gastos com fertilizantes fosfatados. Dessa forma, objetivou-se com este trabalho isolar e caracterizar bactérias solubilizadoras de fosfato da rizosfera de Eucalyptus sp., visando à sua coinoculação com fungos ectomicorrízicos. Entre os 24 isolados de bactérias originários do solo rizosférico de eucalipto, 12 são do filo $\gamma$-Proteobacteria e pertencentes à família Enterobacteriaceae (Enterobacter, Kluyvera e Klebsiella); 9 do filo $\beta$-Proteobacteria (Burkholderia); 1 do filo Actinobacteria (Curtobacterium); e 1 do filo Firmicutes (Enterococcus). O índice de solubilização de fosfato, calculado dividindo-se o diâmetro do halo de clareamento pelo diâmetro da colônia, variou de 0 a 11, sendo Enterococcus avium a espécie com o maior potencial de solubilização de $\mathrm{CaHPO}_{4}$ in vitro. A produção de acidez em meio glicose-extrato de levedura pelos isolados bacterianos rizosféricos foi significativa, no entanto a capacidade de solubilização de $\mathrm{CaHPO}_{4}$ não se correlacionou com a acidificação do meio. Alguns isolados bacterianos promoveram forte inibição do crescimento de Pisolithus sp., isolado H4111, enquanto outros não causaram esse fenômeno. Os isolados RE 56 (Enterococcus avium), RE 41 (Burkholderia cepacea), RE 52 e RE 30 (ambos Burkholderia pyrrocinia) foram aqueles que apresentaram maior potencial para utilização em experimentos de coinoculação com fungos ectomicorrízicos.
\end{abstract}

Palavras-chave: Microbiologia do solo; Fungos micorrízicos; Compatibilidade.

\section{ISOLATION AND CHARACTERIZATION OF PHOSPHATE SOLUBILIZING BACTERIA FROM Eucalyptus sp. RHIZOSPHERE}

\begin{abstract}
The inoculation of phosphate solubilizing microorganisms, with or without mycorrhizal fungi, can be an alternative to reduce de production costs of eucalyptus due to the decrease in phosphate fertilization spending. Thus, the objective of this work was to isolate and characterize phosphate solubilizing bacteria from the rhizosphere of Eucalyptus sp. aiming their co-inoculation with ectomycorrhizal fungi. Among the 24 isolates of bacteria originating from the rhizosphere soil of Eucalyptus, 12 are from phylum $\gamma$-Proteobacteria belonging to the family Enterobacteriaceae (Enterobacter, Kluyvera and Klebsiella); 9 from $\beta$-Proteobacteria (Burkholderia); one from Actinobacteria (Curtobacterium) and one from Firmicutes (Enterococcus). The phosphate solubilization index, calculated by dividing the diameter of the halo of bleaching by the diameter of the colony, ranged from 0 to 11, with the species Enterococcus avium showing the greatest potential to solubilize $\mathrm{CaHPO}_{4}$ in vitro. The production of acidity in the Glucose-Yeast Extract media by the rhizosphere bacterial isolates was significant, however, $\mathrm{CaHPO}_{4}$ solubilization ability is
\end{abstract}


not correlated with the acidification of the medium. Some bacterial isolates promoted strong inhibition
of growth of Pisolithus sp., isolate H4111, while others did not cause this phenomenon. The isolates RE
56 (Enterococcus avium), RE 41 (Burkholderia cepacea), RE 52 and RE 30 (both Burkholderia pyrrocinia)
were those which showed the highest potential for utilization in co-inoculation experiments with ectomycorrhizal
fungi.

Keywords: Soil microbiology; Mycorrhizal fungi; Compatibility.

\section{INTRODUÇÃO}

Os latossolos constituem a classe de solos predominantes no Brasil e na região de Viçosa, MG. São solos intensamente intemperizados, apresentando fertilidade relativamente baixa, dada a limitada disponibilidade de nutrientes essenciais ao crescimento vegetal, como fósforo, cálcio, magnésio, potássio, entre outros (EMBRAPA, 1999). Nesses solos, a utilização de eucalipto para fins de reflorestamento é interessante devido às características dessa planta, a exemplo da sua capacidade de tolerar baixa fertilidade e acidez elevada (BARROS et al., 1981). Mas, mesmo com essas características, torna-se necessária a utilização de fertilizantes para obtenção de boa produtividade (BARROS et al., 1981).

As formas de adubação fosfatada convencionais baseiam-se na aplicação de fertilizantes químicos de alto custo, o que requer a aplicação de doses superiores às necessárias ao crescimento da planta, tendo em vista que cerca de $90 \%$ do fósforo aplicado é rapidamente adsorvido nas partículas de argila (GONÇALVES et al., 1985). Uma forma de reduzir os custos com a aplicação de fósforo é a utilização de fosfatos naturais, o que tem como inconveniente o fato de apresentarem baixa solubilidade e, portanto, serem pouco disponíveis às plantas.

O que pode viabilizar a utilização de fosfatos naturais é o emprego de micro-organismos com capacidade de solubilizar essa fonte de fósforo. Vários estudos têm sido feitos visando ao isolamento de micro-organismos solubilizadores de fosfato e sua posterior inoculação em plantas. A inoculação de micro-organismos capazes de solubilizar formas insolúveis de fosfato (CHAIHARN; LUMYONG, 2011; AZZIZ et al., 2012; DE BOLLE et al., 2013) ou sua coinoculação com fungos micorrízicos (SAXENA et al., 2014) é capaz de promover maior crescimento de plantas. No entanto, os efeitos positivos da coinoculação de bactérias solubilizadoras de fosfato e fungos micorrízicos sobre o crescimento e absorção de nutrientes dependem da compatibilidade entre os isolados inoculados (BIDONDO et al., 2012).

Os micro-organismos presentes no solo interagem entre si de diversas formas, podendo apresentar relações positivas, neutras ou negativas (JOHANSSON et al., 2004). A dinâmica das relações entre fungos micorrízicos e bactérias da rizosfera é uma área pouco explorada. Sabe-se, todavia, que a rizosfera e a endorrizosfera são os principais reservatórios de bactérias antagonistas a fungos fitopatogênicos, como Verticillium dahliae e Rizoctonia solani (BERG et al., 2005), e que também podem ser antagonistas de fungos micorrízicos (JOHANSSON et al., 2004). Diferenças consideráveis ocorrem entre fungos micorrízicos em sua colonização do rizoplano, tanto na presença quanto na ausência de bactérias. Os fungos micorrízicos Rhizopogon luteolus e Thelephora terrestris geralmente colonizam bem as raízes de Pinus radiata na ausência de bactérias, porém o fungo Pisolithus tinctorius apresenta menor desempenho sob essas condições (BOWEN et al., 1979). Bidondo et al. (2012) observaram que a maior disponibilidade de fósforo proporcionada às plantas pela inoculação de bactérias solubilizadoras de fosfato reduziu a colonização radicular por fungos micorrízicos.

O isolamento de bactérias capazes de solubilizar fosfatos naturais, com o objetivo de utilizá-las em programa de coinoculação com fungos micorrízicos, pode constituir alternativa para suprir as necessidades de fosfato e reduzir custos na produção de eucalipto, pela diminuição dos gastos com fertilizantes químicos (KHAN et al., 2007). O objetivo deste trabalho foi isolar e caracterizar bactérias solubilizadoras de fosfato da rizosfera de Eucalyptus sp., visando à coinoculação com fungos ectomicorrízicos.

\section{MATERIAL E MÉTODOS}

Os experimentos foram conduzidos no Laboratório de Associações Simbióticas Micorrízicas do Departamento de Microbiologia da Universidade Federal 
de Viçosa, localizado no Instituto de Biotecnologia Aplicada à Agropecuária (BIOAGRO), Viçosa, MG.

Cinco amostras compostas contendo $50 \mathrm{~g}$ de solo rizosférico, definido como aquele que permanece aderido às raízes após a agitação, foram coletadas a partir do sistema radicular de três plantas de Eucalyptus sp., na camada de $0-20 \mathrm{~cm}$ de profundidade e a uma distância máxima de $1,0 \mathrm{~m}$ do caule. As amostras foram imediatamente transportadas para o laboratório em caixa de isopor com gelo. De cada amostra, $1 \mathrm{~g}$ de solo foi diluído serialmente até $10^{-6}$ em solução salina ( $\mathrm{NaCl}$ a $\left.0,85 \%\right)$. Alíquotas de $0,1 \mathrm{~mL}$ das diluições foram inoculadas em placas de Petri contendo meio Glicose-Extrato de Levedura (GEL), acrescidas de fosfato de cálcio $\left(\mathrm{CaHPO}_{4}\right)$ e incubadas na temperatura de $28^{\circ} \mathrm{C}$ até o surgimento de colônias. As bactérias capazes de solubilizar fosfato de cálcio foram identificadas pela presença de halo transparente ao redor da colônia. As bactérias foram reinoculadas em meio GEL contendo fosfato de cálcio, para isolamento de culturas puras e confirmação da capacidade de solubilização de fosfato. Cada isolado recebeu um código de identificação composto pelas letras "RE" e uma numeração. Para os experimentos subsequentes, os isolados foram mantidos ativos por meio de sua inoculação, a cada sete dias, em novas placas contendo o meio GEL. Para conservação dos isolados, estes foram cultivados em meio caldo nutriente por $8 \mathrm{~h}$ a $28{ }^{\circ} \mathrm{C}$, e, posteriormente, uma alíquota de $1 \mathrm{~mL}$ do caldo nutriente foi misturada a $1 \mathrm{~mL}$ de glicerol $80 \%$, congelada em nitrogênio líquido e mantida em ultrafreezer a $-86^{\circ} \mathrm{C}$. Quando necessário, as culturas estocadas em ultrafreezer foram ativadas pela inoculação em $25 \mathrm{~mL}$ de caldo nutriente, seguido de incubação a $28^{\circ} \mathrm{C}$ por $8 \mathrm{~h}$.

Para a caracterização morfológica e identificação dos isolados, culturas previamente inoculadas em meio ágar-nutriente e incubadas a $28^{\circ} \mathrm{C}$, por $12-18 \mathrm{~h}$, foram utilizadas para a confecção de esfregaços, visando caracterizar a forma, a coloração de Gram e as dimensões celulares dos isolados. O diâmetro e comprimento celulares foram medidos utilizando-se micrômetro ocular de fio móvel Olympus, modelo OSM 203749, e o resultado, expresso como a média de 20 medições tomadas de cada variável. A espécie dos isolados bacterianos foi determinada por meio da análise dos ésteres metílicos de ácidos graxos (GC-FAME) [Sherlock, Microbial Identification System versão 4.0], de acordo com a metodologia descrita por Sasser (2006).
Para determinação do potencial de solubilização de fosfato dos isolados, duas placas de Petri com 25 $\mathrm{mL}$ de meio GEL contendo fosfato de cálcio foram inoculadas com cada isolado bacteriano, por meio da realização de três picadas equidistantes na superfície do meio. As placas inoculadas foram incubadas a 28 ${ }^{\circ} \mathrm{C}$ e avaliadas diariamente em relação ao aparecimento de halo de solubilização. O potencial de solubilização foi determinado aos 7, 14 e 21 dias de incubação, dividindo-se o diâmetro do halo pelo diâmetro da colônia, conforme descrito por Kumar e Narula (1999). Os dados foram submetidos à análise de variância e as médias dos tratamentos, ao teste de Tukey a $5 \%$ de probabilidade. Para verificar a capacidade dos isolados em reduzir o pH do meio de cultura, tubos de ensaio contendo $10 \mathrm{~mL}$ do meio GEL foram inoculados com cada um dos isolados bacterianos e incubados a $28^{\circ} \mathrm{C}$, por 48 h. Ao final do período de incubação, mediu-se o pH do meio utilizando potenciômetro LabTrade ${ }^{\circledR}$. O experimento foi realizado em três repetições. Os dados foram submetidos à análise de variância e as médias, comparadas pelo teste de Scott-Knott a 5\% de probabilidade.

Para determinação da compatibilidade in vitro entre os isolados bacterianos e o fungo ectomicorrízico Pisolithus sp., dois discos de ágar contendo micélio do isolado H4111, retirados das bordas de colônias cultivadas em meio $\mathrm{MNM}$, por 15 dias a $28^{\circ} \mathrm{C}$, foram inoculados a $3 \mathrm{~cm}$ de distância em placas de Petri contendo o mesmo meio. Após três dias de incubação a $28^{\circ} \mathrm{C}$, inoculou-se cada isolado bacteriano por meio de uma estria entre dois discos de ágar. As placas foram incubadas por mais 15 dias a $28^{\circ} \mathrm{C}$, para verificação da ocorrência de inibição do crescimento do fungo pelos isolados bacterianos. O experimento foi realizado com três repetições.

A classificação dos níveis de interação entre os isolados bacterianos e o fungo foi a seguinte:

I - Compatibilidade: colônias com crescimento normal; hifas crescem sobre a estria bacteriana.

II - Inibição fraca: colônias com densidade micelial normal; hifas aproximam-se da estria bacteriana, mas não ocorre contato.

III - Inibição média: colônias com densidade micelial normal; crescimento micelial claramente desfavorecido no lado da estria.

Revista Árvore, Viçosa-MG, v.40, n.1, p.125-134, 2016

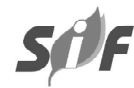


IV - Inibição forte: redução drástica no diâmetro da colônia e na densidade de hifas, às vezes com forte repulsão do micélio em relação à estria bacteriana.

A produção de pigmento marrom-escuro pelo fungo também foi avaliada como indício de incompatibilidade, ou seja:

I - Ausência de pigmentação na colônia fúngica e no meio de cultura.

II - Presença abundante de pigmentos na colônia fúngica ou no meio de cultura.

III - Presença abundante de pigmentos na colônia fúngica e no meio de cultura.

\section{RESULTADOS}

Inicialmente, todos os isolados apresentaram o halo de solubilização de fosfato de cálcio característico em meio GEL. No entanto, alguns perderam a capacidade de solubilização ao longo dos ciclos de cultivo. A caracterização morfológica e identificação dos isolados de bactérias solubilizadoras de fosfato mostram a predominância de bacilos gram-negativos e de bactérias da família Enterobacteriaceae (Tabela 1). Com exceção dos isolados RE 56, um coco gram-positivo e RE 35, um bacilo gram-positivo, todos os outros apresentaram a forma de bacilo curto, com dimensões entre 0,54 $1,00 \times 1,07-2,52 \mu \mathrm{m}$ (Tabela 1).

Os isolados bacterianos obtidos a partir da rizosfera de Eucalyptus sp. diferiram quanto à capacidade de solubilização de fosfato de cálcio in vitro (Tabela 2 ). Com sete dias de crescimento, os isolados demonstraram um índice de solubilização médio entre zero e 9,57. Após 14 dias de crescimento, as médias variaram entre zero e 10,25, e ao final dos 21 dias de incubação os isolados que mantiveram a capacidade de solubilização apresentaram índices variando entre 0,75 e 11,00. Ao fim dos 21 dias, os isolados com maior índice de solubilização foram RE 56 e RE 41, de E. avium e $B$. cepacea, respectivamente, sendo o primeiro significativamente maior, apesar de apresentar o menor crescimento entre todos os isolados.

Os valores de $\mathrm{pH}$ do meio GEL líquido mostraram diferenças significativas de acordo com o isolado bacteriano inoculado (Tabela 2), variando entre 3,98 e 4,39, enquanto o controle apresentou média de 4,45. A maior redução do $\mathrm{pH}$ do meio, em relação ao controle, ocorreu com a inoculação de Entercoccus avium, que também foi o que apresentou maior índice de solubilização em meio sólido (Tabela 2). Alguns isolados que promoveram significativa redução do $\mathrm{pH}$ (RE 1, RE 13, RE 43, RE 44, RE 45, RE 46, RE 47, RE 48, RE 50, RE 51 e RE 54), com valores entre 4,03 e 4,09, tiveram índices de solubilização em meio sólido menores do que 1,50 (Tabela 2). Já os isolados RE 30 e RE 41, que apresentaram, respectivamente, valores de $\mathrm{pH}$ de 4,39 e 4,31, apresentaram índices de solubilização em meio sólido de 2,04 e 4,15, respectivamente (Tabela 2).

O crescimento do fungo ectomicorrízico Pisolithus sp. foi inibido pela presença de alguns isolados bacterianos (Tabela 2). Essa inibição apresentou diferentes níveis, que foram detectados por meio da observação do padrão de crescimento do micélio (Figura 1). Burkholderia cepacea, isolado RE 53, inibiu severamente o crescimento radial da colônia de Pisolithus sp., levando à produção de micélio aéreo pouco denso. Enterobacter intermedius, isolado RE 1; e Kluyvera ascorbata, isolado RE 13, inibiram severamente o crescimento de Pisolithus sp. (Figura 1F), o mesmo ocorrendo com Klebsiella pneumoniae, isolado RE 54 (Figura 1E).

\section{DISCUSSÃO}

Neste trabalho foram obtidos 24 isolados bacterianos, todos com capacidade para solubilizar fosfato. No entanto, ao longo das sucessivas repicagens, alguns isolados perderam a capacidade de solubilização, fato já descrito por outros autores (ILLMER; SCHINNER, 1992; MULETA et al., 2013). Alterações na capacidade de solubilização de fosfato de isolados podem ocorrer ao longo de sucessivos ciclos de cultivo, levando à perda, como observado neste trabalho, ou ao aumento da capacidade (ILLMER; SCHINNER, 1992). O aumento ou a perda da capacidade de solubilização de fosfato estão relacionados à adaptação dos isolados a diferentes condições de disponibilidade de fósforo no meio de cultivo.

Entre os isolados, foi observado predomínio de bacilos gram-negativos pertencentes à família Enterobacteriaceae, e as dimensões dos isolados são condizentes com as descritas anteriormente (BRENNER, 1980). Em estudo que caracterizou 13 bactérias solubilizadoras de fosfato, isoladas a partir de diferentes plantas cultivadas na Coreia, também foi observada dominância de estirpes dessa mesma família (CHUNG et al., 2005). Entre os gêneros obtidos neste trabalho, os mais frequentes foram Burkholderia, Kluyvera e Klebsiella (Tabela 2). Algumas das espécies desses 
Tabela 1 - Identificação, gram, forma e dimensões celulares de isolados bacterianos solubilizadores de fosfato isolados da rizosfera de Eucalyptus sp. em meio glicose-extrato de levedura.

Table 1 - Identification, gram, shape and cell dimensions of phosphate solubilizing bacterial isolates from Eucalyptus sp. rhizosphere isolated in glucose-yeast extract medium.

\begin{tabular}{|c|c|c|c|c|c|}
\hline \multirow[t]{2}{*}{ Isolado } & \multirow[t]{2}{*}{ Espécie } & \multirow[t]{2}{*}{ Gram } & \multirow[t]{2}{*}{ Forma } & \multicolumn{2}{|c|}{ Dimensões $(\mu \mathrm{m})$} \\
\hline & & & & Comprimento & Diâmetro \\
\hline RE 1 & Enterobacter intermedius & Negativo & Bacilo & 1,51 & 0,61 \\
\hline RE 3 & Burkholderia cepacea & Negativo & Bacilo & 2,52 & 0,88 \\
\hline RE 9 & Não identificado & Negativo & Bacilo & 1,58 & 0,66 \\
\hline RE 10 & Burkholderia cepacea & Negativo & Bacilo & 1,55 & 0,70 \\
\hline RE 12 & Kluyvera ascorbata & Negativo & Bacilo & 1,28 & 0,65 \\
\hline RE 13 & Kluyvera ascorbata & Negativo & Bacilo & 1,73 & 0,98 \\
\hline RE 30 & Burkholderia pyrrocinia & Negativo & Bacilo & 1,90 & 0,89 \\
\hline RE 34 & Burkholderia pyrrocinia & Negativo & Bacilo & 1,92 & 1,00 \\
\hline RE 35 & $\begin{array}{l}\text { Curtobacterium flaccumfaciens } \\
\text { poinsettiae }\end{array}$ & Positivo & Bacilo & 1,37 & 0,59 \\
\hline RE 37 & Burkholderia cepacea & Negativo & Bacilo & 1,77 & 0,86 \\
\hline RE 41 & Burkholderia cepacea & Negativo & Bacilo & 1,99 & 0,93 \\
\hline RE 43 & Kluyvera ascorbata & Negativo & Bacilo & 1,26 & 0,59 \\
\hline RE 44 & Kluyvera ascorbata & Negativo & Bacilo & 1,07 & 0,54 \\
\hline RE 45 & Kluyvera ascorbata & Negativo & Bacilo & 1,18 & 0,66 \\
\hline RE 46 & Kluyvera ascorbata & Negativo & Bacilo & 1,41 & 0,61 \\
\hline RE 47 & Kluyvera ascorbata & Negativo & Bacilo & 1,74 & 0,81 \\
\hline RE 48 & Kluyvera ascorbata & Negativo & Bacilo & 1,64 & 0,64 \\
\hline RE 49 & Burkholderia pyrrocinia & Negativo & Bacilo & 1,98 & 0,75 \\
\hline RE 50 & Enterobacter cancerogenus & Negativo & Bacilo & 1,94 & 0,78 \\
\hline RE 51 & Klebsiella pneumoniae pneumoniae & Negativo & Bacilo & 1,42 & 0,60 \\
\hline RE 52 & Burkholderia pyrrocinia & Negativo & Bacilo & 1,94 & 0,93 \\
\hline RE 53 & Burkholderia cepacea & Negativo & Bacilo & 1,90 & 0,77 \\
\hline RE 54 & Klebsiella pneumoniae ozaenae & Negativo & Bacilo & n.d. & n.d. \\
\hline RE 56 & Enterococcus avium & Positivo & Coco & 0,95 & 0,95 \\
\hline
\end{tabular}

gêneros, B. cepacea e K. pneumoniae, apesar de serem comumente encontradas no solo, podem ser patógenos oportunistas no homem (VIAL et al., 2011).

Algumas das espécies isoladas podem ser também promotoras do crescimento vegetal, e indivíduos da espécie K. pneumoniae são capazes de fixar $\mathrm{N}_{2}$ atmosférico (RUEDA-PUENTE, 2004). Isolados de $B$. cepacea têm capacidade de promover o crescimento de plantas, podendo atuar no controle de patógenos ou na degradação de substâncias recalcitrantes (VIAL et al., 2011). Isolados de K. ascorbata são capazes de promover o crescimento vegetal por meio da mitigação dos efeitos fitotóxicos do chumbo, zinco e níquel quando presentes no solo, além de fornecerem um suprimento adequado de ferro às plantas (BURD et al., 2000).

O índice de solubilização dos isolados variou em relação ao tempo e ao isolado em foco, apresentando valores entre zero e 11,00. Com exceção dos isolados RE 56, de Enterococcus avium, e RE 41, de B. cepacea, que apresentaram índices de solubilização superiores a 2,3, os demais isolados solubilizadores apresentaram índices variando entre 1 e 2,04. Resultados semelhantes foram observados por Muleta et al. (2013) em bactérias isoladas da rizosfera de Coffea arabica. Diferentemente do que foi verificado neste trabalho, Chung et al. (2005) relataram maior solubilização de fosfato pelas espécies $K$. ascorbata e K. pneumoniae, quando isoladas da rizosfera de plantas cultivadas na Coreia.

Variações no potencial de solubilização de fosfato por micro-organismos têm sido observadas por vários autores, sendo utilizada como uma das principais características no processo de seleção (AZZIZ et al., 2012; DE BOLLE et al., 2013; MULETA et al., 2013). Os micro-organismos solubilizadores de fosfato podem ser classificados quanto ao seu índice de solubilização (SILVA FILHO; VIDOR, 2000). Segundo esses autores, os isolados que apresentam índices menores que 2 são classificados como pouco solubilizadores e isolados

Revista Árvore, Viçosa-MG, v.40, n.1, p.125-134, 2016 
Tabela 2 - Índices de solubilização de fosfato, pH e compatibilidade in vitro entre bactérias solubilizadoras de fosfato isoladas da rizosfera de Eucalyptus sp. e isolado fúngico H4 111 de Pisolithus sp.

Table 2 - Phosphate solubilization index, pH and in vitro compatibility between phosphate solubilizing bacterial isolates from Eucalyptus sp. rhizosphere and fungal isolate H4 111 of Pisolithus sp.

\begin{tabular}{|c|c|c|c|c|c|c|}
\hline \multirow[t]{2}{*}{ Isolado } & \multicolumn{3}{|c|}{ Índice ${ }^{1 /}$} & $\mathrm{pH}^{2 /}$ & \multirow[t]{2}{*}{ Inibição $^{4 /}$} & \multirow[t]{2}{*}{ Pigmentação ${ }^{5 /}$} \\
\hline & 7 dias & 14 dias & 21 dias & $48 \mathrm{~h}$ & & \\
\hline Controle & - & - & - & $4,45 \mathrm{~A}$ & - & - \\
\hline RE 1 & $1,82 \mathrm{~B}, \mathrm{a}^{3 /}$ & $1,41 \mathrm{C}, \mathrm{a}$ & $1,37 \mathrm{D}, \mathrm{a}$ & $4,05 \quad \mathrm{~F}$ & $+1+$ & + \\
\hline RE 3 & $0,00 \mathrm{C}, \mathrm{a}$ & $0,00 \mathrm{D}, \mathrm{a}$ & $0,00 \mathrm{E}, \mathrm{a}$ & $4,34 \mathrm{C}$ & - & - \\
\hline RE 9 & $0,00 \mathrm{C}, \mathrm{a}$ & $0,00 \mathrm{D}, \mathrm{a}$ & $0,73 \mathrm{D}, \mathrm{a}$ & $4,26 \mathrm{D}$ & - & - \\
\hline RE 10 & $1,57 \mathrm{~B}, \mathrm{a}$ & $1,64 \mathrm{C}, \mathrm{a}$ & $1,89 \mathrm{C}, \mathrm{a}$ & $4,32 \mathrm{C}$ & - & - \\
\hline RE 12 & $0,00 \mathrm{C}, \mathrm{a}$ & $0,00 \mathrm{D}, \mathrm{a}$ & $0,00 \mathrm{E}, \mathrm{a}$ & $4,12 \mathrm{E}$ & - & - \\
\hline RE 13 & $1,29 \mathrm{~B}, \mathrm{a}$ & $1,00 \mathrm{C}, \mathrm{a}$ & $0,00 \mathrm{E}, \mathrm{a}$ & $4,04 \mathrm{~F}$ & $+1+$ & + \\
\hline RE 30 & $0,60 \mathrm{C}, \mathrm{b}$ & $2,11 \mathrm{~B}, \mathrm{a}$ & $2,04 \mathrm{C}, \mathrm{a}$ & $4,39 \mathrm{~B}$ & + & + \\
\hline RE 34 & $1,30 \mathrm{~B}, \mathrm{~b}$ & $2,78 \mathrm{~B}, \mathrm{a}$ & $1,53 \mathrm{D}, \mathrm{b}$ & $4,38 \quad \mathrm{~B}$ & + & - \\
\hline RE 35 & $0,00 \mathrm{C}, \mathrm{a}$ & $0,00 \mathrm{D}, \mathrm{a}$ & $0,00 \mathrm{E}, \mathrm{a}$ & $4,18 \quad E$ & $+1+$ & + \\
\hline RE 37 & $0,00 \mathrm{C}, \mathrm{a}$ & $0,49 \mathrm{D}, \mathrm{a}$ & $0,75 \mathrm{D}, \mathrm{a}$ & $4,52 \mathrm{~A}$ & + & - \\
\hline RE 41 & $1,69 \mathrm{~B}, \mathrm{~b}$ & $3,00 \mathrm{~B}, \mathrm{ab}$ & $4,15 \mathrm{~B}, \mathrm{a}$ & $4,31 \mathrm{C}$ & + & - \\
\hline RE 43 & $1,18 \mathrm{~B}, \mathrm{a}$ & $1,16 \mathrm{C}, \mathrm{a}$ & $1,22 \mathrm{D}, \mathrm{a}$ & $4,05 \quad \mathrm{~F}$ & ++ & - \\
\hline RE 44 & $1,31 \mathrm{~B}, \mathrm{a}$ & $1,06 \mathrm{C}, \mathrm{a}$ & $1,19 \mathrm{D}, \mathrm{a}$ & $4,03 \quad \mathrm{~F}$ & - & - \\
\hline RE 45 & $1,50 \mathrm{~B}, \mathrm{a}$ & $1,54 \mathrm{C}, \mathrm{a}$ & $1,51 \mathrm{D}, \mathrm{a}$ & $4,04 \mathrm{~F}$ & + & - \\
\hline RE 46 & $1,53 \mathrm{~B}, \mathrm{a}$ & $1,19 \mathrm{C}, \mathrm{a}$ & $1,17 \mathrm{D}, \mathrm{a}$ & $4,09 \quad \mathrm{~F}$ & $+1+$ & + \\
\hline RE 47 & $1,00 \mathrm{~B}, \mathrm{a}$ & $1,18 \mathrm{C}, \mathrm{a}$ & $1,18 \mathrm{D}, \mathrm{a}$ & $4,08 \quad \mathrm{~F}$ & + & - \\
\hline RE 48 & $1,09 \mathrm{~B}, \mathrm{a}$ & $1,00 \mathrm{C}, \mathrm{a}$ & $1,24 \mathrm{D}, \mathrm{a}$ & $4,03 \quad \mathrm{~F}$ & + & - \\
\hline RE 49 & $0,63 \mathrm{C}, \mathrm{a}$ & $1,52 \mathrm{C}, \mathrm{a}$ & $1,91 \mathrm{C}, \mathrm{a}$ & $4,31 \mathrm{C}$ & - & - \\
\hline RE 50 & $1,86 \mathrm{~B}, \mathrm{a}$ & $1,43 \mathrm{C}, \mathrm{a}$ & $1,00 \mathrm{D}, \mathrm{a}$ & $4,04 \quad F$ & + & - \\
\hline RE 51 & $1,06 \mathrm{~B}, \mathrm{a}$ & $1,41 \mathrm{C}, \mathrm{a}$ & $1,18 \mathrm{D}, \mathrm{a}$ & $4,06 \mathrm{~F}$ & + & - \\
\hline RE 52 & $0,40 \mathrm{C}, \mathrm{b}$ & $1,46 \mathrm{C}, \mathrm{ab}$ & $2,03 \mathrm{C}, \mathrm{a}$ & $4,33 \mathrm{C}$ & - & - \\
\hline RE 53 & $1,10 \mathrm{~B}, \mathrm{a}$ & $1,18 \mathrm{C}, \mathrm{a}$ & $1,12 \mathrm{D}, \mathrm{a}$ & $4,22 \mathrm{D}$ & $+1+$ & - \\
\hline RE 54 & $1,31 \mathrm{~B}, \mathrm{a}$ & $1,00 \mathrm{C}, \mathrm{a}$ & $1,00 \mathrm{D}, \mathrm{a}$ & $4,09 \quad \mathrm{~F}$ & $+1+$ & + \\
\hline RE 56 & $9,57 \mathrm{~A}, \mathrm{~b}$ & $10,25 \mathrm{~A}, \mathrm{a}$ & $11,00 \mathrm{~A}, \mathrm{a}$ & $3,72 \mathrm{G}$ & - & - \\
\hline
\end{tabular}

1/Índice $=$ diâmetro do halo/diâmetro da colônia. As medidas foram tomadas de colônias crescidas em meio glicose-extrato de levedura a $28{ }^{\circ} \mathrm{C}$

2 /Valores de $\mathrm{pH}$ medidos em meio glicose-extrato de levedura líquido inoculado com os isolados bacterianos e incubado a $28{ }^{\circ} \mathrm{C}$.

$3 / \mathrm{Na}$ linha, médias seguidas pela mesma letra minúscula não diferem entre si, pelo teste de Tukey a 5\% de probabilidade. Na coluna, médias seguidas pela mesma letra maiúscula não diferem entre si, pelo teste de Scott-Knott a 5\% de probabilidade. 4/Inibição:

I - Colônias com crescimento normal; hifas crescem sobre a estria bacteriana (-).

II - Colônias com densidade micelial normal; hifas aproximam-se da estria bacteriana, mas não ocorre contato (+).

III - Colônias com densidade micelial normal; crescimento micelial claramente desfavorecido no lado da estria (++).

IV - Redução drástica no diâmetro e densidade de hifas da colônia, às vezes com forte repulsão do micélio em relação à estria bacteriana $(+++)$.

5/Pigmentação:

I - Ausência de pigmentação na colônia fúngica e no meio de cultura (-)

II - Presença abundante de pigmentos na colônia fúngica ou no meio de cultura $(+)$.

III - Presença abundante de pigmentos na colônia fúngica e no meio de cultura (++).

com índices entre 2 e 3 , como isolados de potencial médio, enquanto aqueles com índices maiores que 3 , muito solubilizadores. Baseado nesse sistema, os isolados RE 1, RE 3, RE 9, RE 10, RE 12, RE 13, RE 34, RE 35, RE 37, RE 43, RE 44, RE 45, RE 46, RE 47, RE 48, RE 49, RE 50, RE 51, RE 53 e RE 54 foram considerados pouco solubilizadores, demonstrando índices entre zero e 1,51. Os isolados RE 30 e RE 52 foram concebidos como solubilizadores médios, com índices de 2,04 e
2,03, respectivamente, enquanto os isolados RE $41 \mathrm{e}$ RE 56, como muito solubilizadores, apresentando índices de 4,15 e 11,00 , respectivamente.

Neste trabalho, observou-se que os isolados que apresentaram maior índice de solubilização foram também os que promoveram maior redução do $\mathrm{pH}$ do meio de cultura. Além disso, os isolados com baixo potencial de solubilização promoveram menor redução no $\mathrm{pH}$. 

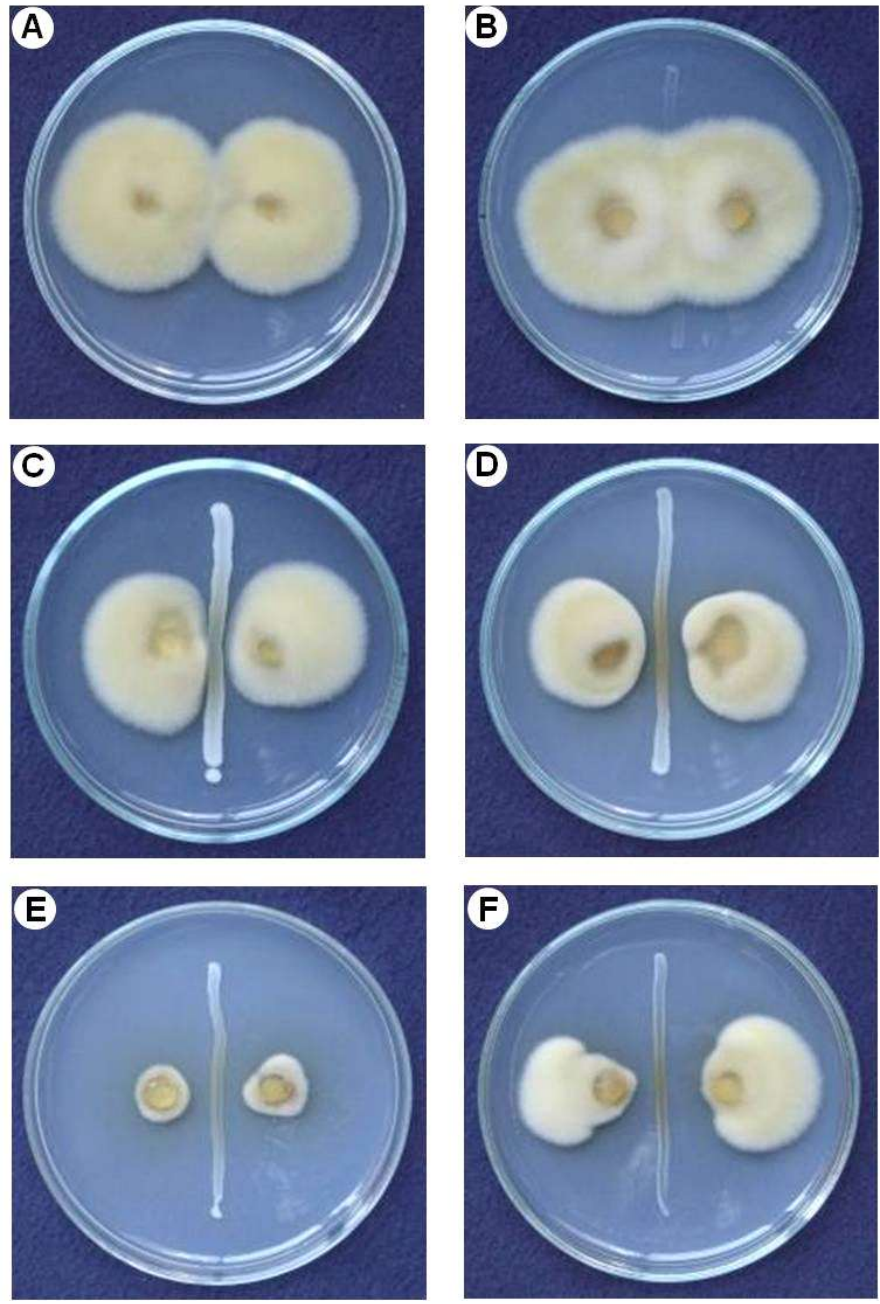

Figura 1 - Compatibilidade in vitro entre os isolados de bactérias solubilizadoras de fosfato da rizosfera de Eucalyptus sp. e o fungo ectomicorrízico Pisolithus sp., cultivado em meio Merlin-Norkrans-Modificado a $28{ }^{\circ} \mathrm{C}$ por 18 dias. (A) Controle; (B) Isolado RE 56 de Enterococcus avium, não inibitório; (C) Inibição fraca pelo isolado RE 37 de Burkholderia cepacia; (D) Inibição média pelo isolado RE 43 de Kluyvera ascorbata; (E) Inibição forte pelo isolado RE 54 de Klebsiella pneumoniae; e (F) Inibição forte pelo isolado RE 1 de Enterobacter intermedius.

Figure 1 - In vitro compatibility between phosphate solubilizing bacterial isolates from Eucalyptus sp. rhizosphere and the ectomycorrhizae fungus Pisolithus sp., in MNM medium at $28^{\circ} \mathrm{C}$ for 18 days. (A) Control; (B) Isolate RE 56 of Enterococcus avium, not-inhibitory; (C) Weak inhibition by isolate RE 37 of Burkholderia cepacia; (D) Intermediate inhibition by isolate RE 43 of Kluyvera ascorbata; (E) Strong inhibition by isolate RE 54 of Klebsiella pneumoniae; and (F) Strong inhibition by isolate RE 1 of Enterobacter intermedius.

Apesar de não ser possível determinar a correlação entre os dados, visto que foram obtidos em experimentos diferentes, é admissível a hipótese de que o principal mecanismo utilizado pela maioria dos isolados para a solubilização de fosfato de cálcio seja a acidificação do meio. Mendes et al. (2013) verificaram que o principal mecanismo utilizado por fungos para solubilizar fosfato de cálcio foi a acidificação do meio, ao passo que a liberação de ácidos orgânicos é mais importante para a solubilização de fosfatos de rocha. Resultado semelhante foi constatado nos isolados de Penicillium rugulosum, para os quais a solubilização de fosfatos naturais se deve, principalmente, à ação de ácidos orgânicos (REYES et al., 2001). 
No caso dos isolados RE 30 e RE 41, que apresentaram, respectivamente, valores de $\mathrm{pH}$ de 4,39 e 4,31 ao fim de $48 \mathrm{~h}$ de crescimento e índices de solubilização de 2,04 e 4,15, respectivamente, outros mecanismos podem estar envolvidos, como a liberação de ácidos orgânicos. Esses dados corroboram relatos prévios da literatura que sugerem que a promoção da acidez do meio não é o único fator que atua na solubilização de fosfato (SILVA FILHO et al., 2002). A atuação de agentes quelantes capazes de reagir com os produtos da solubilização, evitando o retorno do fósforo a formas insolúveis, pode aumentar a capacidade de solubilização (KPOMBLEKOUA; TABATABAI, 1994). A dinâmica de solubilização e imobilização de fósforo pelas células pode ser outro fator importante no deslocamento do equilíbrio da reação a favor da solubilização (SILVA FILHO et al., 2002). Dessa forma, quando a assimilação é superior à solubilização, os produtos da reação estão constantemente em baixas concentrações, o que faz que mais fósforo se torne solúvel.

Isolados de diferentes espécies apresentaram forte inibição ao crescimento do fungo ectomicorrízico Pisolithus sp. isolado H4111, entre elas a espécie B. cepacea, sobre a qual existem relatos sobre sua capacidade de produzir substâncias antifúngicas supressivas a vários patógenos (VIAL et al., 2011). É possível admitir-se que as diferentes espécies de bactérias exibem vários mecanismos de inibição do crescimento fúngico, envolvendo substâncias diferentes. A produção quitinases por bactérias do solo está envolvida na inibição do crescimento de fungos. Estirpes de Pseudomonas que produzem quantidades apreciáveis de quitinases e celulases em meios de cultura levam à inibição do crescimento de Pythium aphanidermatum e Rhizoctonia solani (SINDHU; DADARWAL, 2001).

No entanto, a inibição do crescimento de fungos por bactérias em laboratório é dependente do meio de cultura, existindo pouca relação entre as observações in vitro e o que de fato acontece na rizosfera (VASSILEV et al., 2015). Dessa forma, estudos adicionais deverão ser realizados visando elucidar as interações entre as espécies bacterianas isoladas neste trabalho e o isolado fúngico H4111, na rizosfera de Eucalyptus sp., em condições de casa de vegetação e campo.

\section{CONCLUSÕES}

- Os melhores isolados foram RE 56, RE 41, RE 52 e RE30, que constituem material adequado para testes de coinoculação com fungos ectomicorrízicos.
- As bactérias rizosféricas isoladas apresentaram diferentes graus de compatibilidade in vitro com o fungo ectomicorrízico Pisolithus sp., levando a diferentes padrões de crescimento micelial. Esse dado sugere a necessidade de selecionar as combinações mais compatíveis, visando à coinoculação de bactérias solubilizadoras de fosfato com fungos ectomicorrízicos.

\section{REFERÊNCIAS}

AZZIZ, G.; BAJSA, N.; HAGHJOU, T.; TAULÉ, C.; VALVERDE, Á.; IGUAL, J. M.; ARIAS, A. Abundance, diversity and prospecting of culturable phosphate solubilizing bacteria on soils under crop-pasture rotations in a no-tillage regime in Uruguay. Applied Soil

Ecology, v.61, p.320-326, 2012.

BARROS, N. F.; BRAGA, J. M.; BRANDI, R. M.; DEFELIPO, B. V. Produção de eucalipto em solos de cerrados em resposta à aplicação de NPK e de B e Zn. Revista Árvore, v.5, p.90-103, 1981.

BERG, G.; KRECHEL, A.; DITZ, M.; SIKORA, R.A.; ULRICH, A.; HALLMANN, J. Endophitic and ectophitic potato-associated bacterial communities differ in structure and antagonistic function against plant pathogenic fungi.

FEMS Microbiolology Ecology, v.51, p.215-229, 2005.

BIDONDO, L. F.; BOMPADRE, J.; PERGOLA, M.; SILVANI, V.; COLOMBO, R.; BRACAMONTE, F.; GODEAS, A. Differential interaction between two Glomus intraradices strains and a phosphate solubilizing bacterium in maize

rhizosphere. Pedobiologia, v.55, p.227-232, 2012.

BOWEN, G.D.; THEODOROU, C. Interactions between bacteria and ectomycorrhizal fungi. Soil Biolology and Biochemistry, v.11, n.1, p.119-126, 1979.

BRENNER, D.J.; BERCOVIER, H.; URSING, J.; ALONSO, J.M.; STEIGERWALT, A.G.; FANNING, G.R.; CARTER, G.P.; MOLLARET, H.H. Yersinia intermedia: a new species of Enterobacteriaceae composed of rhamnose-positive, melibiosepositive, raffinose-positive strains (formerly called Yersinia enterocolitica or Yersinia enterocolitica-like). Current

Microbiololgy, v.4, p.207-212, 1980. 
BURD, G.I.; DIXON, D.G.; GLICK, B.R. Plant growth-promoting bacteria that decrease heave metal toxicity in plants. Canadian Journal of Microbiology, v.46, p.237-245, 2000.

CHAIHARN, M.; LUMYONG, S. Screening and optimization of indole-3-acetic acid production and phosphate solubilization from rhizobacteria aimed at improving plant growth. Current Microbiology, v.62, p.173-181, 2011.

CHUNG, H.; PARK, M.; MADHAIYAN, M.; SESHADRI, S.; SONG, J.; CHO, H.; SA, T. Isolation and characterization of phosphate solubilizing bacteria from the rhizosphere of crop plants of Korea. Soil Biology Biochemistry, v.10, p.1970-1974, 2005.

DE BOLLE, S.; GEBREMIKAEL, M. T.; MAERVOET, V.; DE NEVE, S. Performance of phosphate-solubilizing bacteria in soil under high phosphorus conditions. Biology and Fertility of Soils, v.49, p.705-714, 2013.

EMPRESA BRASILEIRA DE PESQUISA AGROPECUÁRIA - EMBRAPA. Centro Nacional de Pesquisa de Solos. Sistema Brasileiro de Classificação de Solos. Brasília: EMBRAPA Solos, 1999.

GONÇALVES, J.L.M.; FIRME, D.J.; NOVAIS, R.F.; RIBEIRO, A.C. Cinética de adsorção de fósforo em solos de cerrado. Revista Brasileira de Ciência do Solo, v.9, n.2, p.107-111, 1985.

ILLMER, P.; SCHINNER, F. Solubilization of inorganic phosphates by microorganisms isolated from forest soils. Soil Biology Biochemistry, v.24, n.4, p.389-395, 1992.

JOHANSSON, J.F.; PAUL, L.R.; FINLAY, R.D. Microbial interactions in the mycorrhizosphere and their significance for sustainable agriculture. FEMS Microbiology Ecology, v.48, n.1, p.1-13, 2004.

KHAN, M.S.; ZAIDI, A.; WANI, P.A. Role of phosphate-solubilizing microorganisms in sustainable agriculture - a review. Agronomy for Sustainable Development, v.27, n.1, p.29-43, 2007.
KPOMBLEKOU-A., K.; TABATABAI, M.A. Effect of organic acids on release of phosphorus from phosphate rocks. Soil Science, v.158, p.442$453,1994$.

KUMAR, V.; NARULA, N. Solubilization of inorganic phosphates and growth emergence of wheat as affected by Azotobacter chroococcum mutants. Biology and Fertility of Soils, v.28, n.3, p.301-305, 1999.

MENDES, G.O.; FREITAS, A.L.M.; PEREIRA, O.L.; SILVA, I.R.; VASSILEV, N.B.; COSTA, M.D.

Mechanisms of phosphate solubilization by fungal isolates when exposed to different $\mathrm{P}$ sources. Annals of Microbiology, v.75, n.1, p.1-11, 2013.

MULETA, D.; ASSEFA, F.; BÖRJESSON, E.; GRANHALL, U. Phosphate-solubilising rhizobacteria associated with Coffea arabica L. in natural coffee forests of southwestern Ethiopia. Journal of the Saudi Society of Agricultural

Sciences, v.12, n.1, p.73-84, 2013.

REYES, I.; BERNIER, L.; SIMARD, R.R.; ANTOUN, H. Effect of nitrogen source on the solubilization of different inorganic phosphates by an isolate of Penicillium rugulosum and two UV-induced mutants. FEMS Microbiology Ecology, v.28, p.281-290, 1999.

RUEDA-PUENTE, E.O.; CASTELLANOS, T.; TROYO-DIÉGUEZ, E.; DIAZ, D.E.; LEONALVAREZ, J.L. Effect of Klebsiella pneumoniae and Azospirillum halopraeferens on the growth and development of two Salicornia bigelovii genotypes. Australian Journal of Experimental Agriculture, v.44, n.1, p.6574, 2004.

SASSER, M. Bacterial identification by gas chromatographic analysis of fatty acids methyl esters (GC-FAME). 2006. 6p. (Technical note, 101).

SAXENA, J.; MINAXI; JHA, A. Impact of a phosphate solubilizing bacterium and an arbuscular mycorrhizal fungus (Glomus etunicatum) on growth, yield and $\mathrm{P}$ concentration in wheat plants. CLEAN - Soil Air Water, v.42, n.9, p.1248-1252, 2014.

Revista Árvore, Viçosa-MG, v.40, n.1, p.125-134, 2016

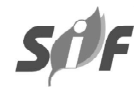


SILVA FILHO, G.N.; NARLOCH, C.; SCHARF, R. Solubilização de fosfatos naturais por microrganismos isolados de cultivos de Pinus e Eucalyptus de Santa Catarina. Pesquisa Agropecuária Brasileira, v.37, n.6, p.847$854,2002$.

SILVA FILHO, G.N.; VIDOR, C. Solubilização de fosfatos por microrganismos na presença de fontes de carbono. Revista Brasileira de Ciência do Solo, v.24, n.2, p.311-329, 2000.

SINDHU, S.S.; DADARWAL, K.R. Chitinolytic and cellulolytic Pseudomonas sp. antagonistic to fungal pathogens enhances nodulation by Mesorhizobium sp. Cicer in chickpea.
Microbiological Research, v.156, p.353-358, 2001.

VASSILEV, N.; VASSILEVA, M.; LOPEZ, A.; MARTOS, V.; REYES, A.; MAKSIMOVIC, I.; EICHLER-LÖBERMANN, B.; MALUSÀ, E. Unexploited potential of some biotechnological techniques for biofertilizer production and formulation. Applied Microbiology and Biotechnology, v.1, n.1, p.1-14, 2015.

VIAL, L.; CHAPALAIN, A.; GROLEAU, M.C.; DÉZIEL, E. The various lifestyles of the Burkholderia cepacia complex species: a tribute to adaptation. Environmental

Microbiology, v.13, n.1, p.1-12, 2011. 